\title{
Analisis Intervesi Fungsi Step Efek Program Tol- Laut Terhadap Pergerakan Harga Saham TMAS.JK
}

\author{
Wigid Hariadi $^{1}$ \\ ${ }^{1}$ IKIP PGRI Jember, wigid.hariadi@gmail.com
}

\begin{abstract}
Intervention analysis is used to evaluate the effect of external events on a time series data. Sea-highway program is one of the leading programs Joko WidodoJusuf Kalla in presidential election 2014. So the author want to modeling the effect from Sea-highway programs on stock price movement in the shipping sector, TMAS.JK (Pelayaran Tempuran Emas tbk). After analyzing, proven that it has happened intervention on movement of daily stock price TMAS.JK caused by Seahighway programs. Intervention I, on 11 August 2014, which was efect as a result of the election of the Joko Widodo-Jusuf kalla pair as President and vice President Republic of Indonesia on 22 july 2014. Intervention II, on 10 november 2014, president Joko Widodo speech in APEC about Sea-highway Program, and offering investment in port construction to foreign country. So that the model of time series analysis that right is intervention analysis model multi input step function, where the model is ARIMA $(2,1,0)$, StepI $(b=0, s=2, r=1)$, StepII $(b=3, s=0, r=1)$.
\end{abstract}

Keywords: Intervention Analysis, Multi Input, Step Function, Sea-highway.

\begin{abstract}
Abstrak. Analisis intervensi digunakan untuk mengevaluasi efek dari peristiwa eksternal pada suatu data time series. Program Tol-Laut merupakan salah satu program unggulan pasangan Joko Widodo-Jusuf Kalla dalam pemilu 2014. sehingga, penulis ingin memodelkan efek dari Program Tol-Laut terhadap pergerakan harga saham dibidang pelayaran, TMAS.JK (Pelayaran Tempuran Emas tbk). Setelah dilakukan analisis data, terbukti bahwa terjadi intervensi pada pergerakan harga saham harian TMAS.JK yang disebabkan oleh efek dari program Tol-Laut. Dimana intervensi I, pada tanggal 11 Agustus 2014, yang diduga sebagai dampak dari terpilihnya pasangan Joko widodo-Jusuf Kalla sebagai presiden dan wakil presiden Republik Indonesia pada tanggal 22 Juli 2014. Intervensi II, pada tanggal 10 November 2014, pidato Presiden Joko Widodo di forum APEC mengenai program tol laut, dan menawarkan investasi dibidang pembangunan pelabuhan kepada bangsa asing. Sehingga model analisis time series yang tepat adalah model analisis intervensi multi input fungsi step, dimana modelnya adalah ARIMA $(2,1,0)$, StepI $(\mathrm{b}=0, \mathrm{~s}=2, \mathrm{r}=1)$, Step II $(\mathrm{b}=3, \mathrm{~s}=0, \mathrm{r}=1)$.
\end{abstract}

Kata kunci: Analisis intervensi, Multi Input, fungsi step, Tol-Laut.

\section{Pendahuluan}

Model autoregressive integrated moving average (ARIMA) merupakan salah satu metode yang populer untuk digunakan dalam peramalan data time series univariat. Namun model ARIMA tidak lagi cocok untuk digunakan pada data yang mengalami perubahan pola yang ekstrim (goncangan data). Karena hal ini dapat mengakibatkan kesalahan dalam identifikasi model yang berakibat pada 
diperolehnya model yang salah (kurang tepat) untuk suatu data time series. Menurut Box, dkk [2], data time series sering terpengaruh oleh peristiwa khusus atau keadaan seperti perubahan kebijakan, aksi mogok kerja, promosi iklan, peraturan lingkungan, dan peristiwa sejenis, dimana peristiwa seperti ini sering disebut peristiwa intervensi. Untuk mengatasi permasalahan diatas, salah satu metode yang dapat digunakan adalah model analisis intervensi. Analisis intervensi ini telah sukses digunakan untuk meneliti dampak pengendalian pencemaran udara dan kebijakan ekonomi (Box and Tiao) [3].

Tol-Laut merupakan salah satu program unggulan pasangan Joko WidodoJusuf Kalla dalam pemilu 2014. Seperti diketahui bahwa apapun program yang pemerintah rencanakan pasti memberikan dampak terhadap pertumbuhan ekonomi baik itu dampak positif maupun negatif. Dalam hal ini penulis tertarik untuk mengetahui apakah program Tol-Laut memberikan efek terhadap pertumbuhan ekonomi, terutama dalam bidang bisnis pelayaran. Sehingga penulis bertujuan untuk memodelkan efek dari Program Tol-Laut terhadap pergerakan harga saham dibidang pelayaran, TMAS.JK (Pelayaran Tempuran Emas tbk). Sehingga nantinya akan diperoleh suatu model yang baik untuk digunakan dalam peramalan harga saham TMAS.JK. Makalah ini ditulis dengan tujuan untuk memberikan hasil kajian teoritik dan aplikasi dari model intervensi fungsi step dengan menggunakan estimasi maksimum likelihood. Kajian terapan dilakukan pada suatu data time series yaitu data harga penutupan saham harian TMAS.JK (Pelayaran Tempuran Emas Tbk), yang merupakan salah satu perusahaan yang bergerak dibidang pelayaran. Data diamati mulai tanggal 1 Januari 2014 sampai 16 Januari 2015. Terpilihnya Pasangan Joko Widodo-Jusuf Kalla sebagai Presiden dan wakil Presiden Republik Indonesia, serta kebijakan yang dibuat mengenai program tol-laut, diduga telah meng-intervensi pergerakan harga saham dibidang bisnis pelayaran.

\section{Tinjauan Pustaka}

\subsection{Model Analisis Intervensi}

Pada analisis intervensi, diasumsikan bahwa peristiwa intervensi telah terjadi pada waktu ke-T dari serangkaian runtun waktu. Hal ini menjadi penting untuk menentukan secara pasti apakah ada perubahan atau efek dari harapan pada data runtun waktu $Y_{t}$ tersebut dimana peristiwa intervensi terjadi. Menurut Wei [5], untuk analisis intervensi multi input, secara umum modelnya adalah sebagai berikut:

$$
\mathrm{Y}_{\mathrm{t}}=\theta_{0}+\sum_{j=1}^{k} \frac{\omega_{j}(B) B^{b_{j}}}{\delta_{j}(B)} I_{j t}+\frac{\theta(B)}{\psi(B)} \varepsilon_{t}
$$

Dimana:

$\theta_{0} \quad=$ konstanta, yang biasanya tidak selalu dituliskan kedalam model.

$$
\begin{aligned}
& \omega_{j}(B)=\omega_{s j}(B)=\omega_{0 j}-\omega_{1 j} B-\omega_{2 j} B^{2}-\ldots-\omega_{s j} B^{s} \\
& \delta_{j}(B)=\delta_{r j}(B)=1-\delta_{1 j} B-\delta_{2 j} B^{2}-\ldots-\delta_{r j} B^{r} \\
& I_{j t}, j=1,2, \ldots, k \text { adalah variabel intervensi, yakni fungsi step atau fungsi pulse. }
\end{aligned}
$$




$$
\begin{aligned}
& \theta(\mathrm{B})=\left(1-\theta_{1} \mathrm{~B}-\theta_{2} \mathrm{~B}^{2}-\ldots-\theta_{\mathrm{q}} \mathrm{B}^{\mathrm{q}}\right) \\
& \psi(\mathrm{B})=\left(1-\phi_{1} \mathrm{~B}-\phi_{2} \mathrm{~B}^{2}-\ldots-\phi_{\mathrm{p}} \mathrm{B}^{\mathrm{p}}\right) \\
& \mathrm{B} \quad=\text { operator mundur, yaitu } B^{k} Y_{t}=Y_{t-k} . \\
& \omega_{\mathrm{Sj}}(\mathrm{B})=\text { operator dari orde } s \\
& \delta_{\mathrm{rj}}(\mathrm{B})=\text { operator dari orde } r
\end{aligned}
$$

Orde $s$ menyatakan lamanya waktu yang dibutuhkan agar efek intervensi menjadi stabil, orde $r$ menyatakan waktu yang dibutuhkan sampai efek intervensi memperlihatkan pola yang jelas, dan orde $b$ menyatakan efek dari suatu intervensi, dimana orde $b$ merupakan waktu tunda (delay) mulai berpengaruhnya intervensi $X$ terhadap $Y$. Menurut Box, dkk [2], terdapat dua jenis analisis intervensi. Yang pertama adalah fungsi step, digunakan untuk merepresentasikan efek dari intervensi yang mempunyai dugaan bahwa efeknya akan terjadi dalam waktu yang lama setelah waktu ke-T. Dapat ditunjukkan indikatornya oleh $S_{t}^{(T)}$, dimana:

$$
\mathrm{S}_{\mathrm{t}}^{(\mathrm{T})}= \begin{cases}0, & t<T \\ 1, & t \geq T\end{cases}
$$

Yang kedua adalah fungsi pulse, digunakan untuk merepresentasikan efek dari intervensi y yang mempunyai dugaan bahwa efeknya akan terjadi sementara dan akan selesai setelah waktu ke-T. Dapat ditunjukkan indikatornya oleh $P_{t}^{(T)}$, dimana:

$$
\mathrm{P}_{\mathrm{t}}^{(\mathrm{T})}= \begin{cases}0, & t \neq T \\ 1, & t=T\end{cases}
$$

\subsection{Metode Estimasi Maksimum Likelihood (MLE)}

Definisi (Bain)[1] : Fungsi densitas bersama dari $\mathrm{n}$ variabel random $\mathrm{X}_{1}, \mathrm{X}_{2}, \ldots$ , $\mathrm{X}_{\mathrm{n}}$ diestimasi dengan $\mathrm{x}_{1}, \mathrm{x}_{2}, \ldots, \mathrm{x}_{\mathrm{n}}$ dilambangkan dengan $\mathrm{f}\left(\mathrm{x}_{1}, \mathrm{x}_{2}, \ldots, \mathrm{x}_{\mathrm{n}} ; \theta\right)$ dengan $\theta$ adalah parameter yang tidak diketahui, maka fungsi likelihood dari $\theta$ adalah :

$$
L(\theta)=f\left(x_{1} ; \theta\right) f\left(x_{2} ; \theta\right) \ldots f\left(x_{n} ; \theta\right)
$$

Menurut Subanar [5], metode maksimum likelihood adalah metode yang paling populer dalam menghasilkan estimator. Misalkan $X_{1}, \ldots, X_{n}$ adalah i.i.d. sampel dari populasi dengan densitas $\mathrm{f}\left(\mathrm{x} \mid \theta_{1} \ldots \theta_{\mathrm{k}}\right)$. Fungsi kemungkinan (likelihood) didefinisikan sebagai:

$$
L(\underline{\theta} \mid \underline{x})=L\left(\theta_{1} \ldots \theta_{k} \mid x_{1} \ldots x_{n}\right)=\prod_{i=1}^{n} f\left(x_{i} \mid \theta_{1} \ldots \theta_{k}\right)
$$

Bila fungsi likelihood terdeferensialkan (dalam $\theta_{\mathrm{i}}$ ), maka calon MLE yang mungkin adalah harga-harga $\left(\theta_{1} \ldots \theta_{\mathrm{k}}\right) . L(\theta)$ akan maksimum jika turunan pertama sama dengan nol. Setiap nilai $\hat{\theta}$ yang memaksimumkan $L(\theta)$ juga akan memaksimumkan $\ln (L(\theta))$. 


\subsection{Estimasi Parameter Model Analisis Intervensi multi input}

Model Analisis intervensi multi input fungsi step ARIMA $(2,1,0)$ step $(b=0$, $\mathrm{s}=2, \mathrm{r}=1)$ step $(\mathrm{b}=3, \mathrm{~s}=0, \mathrm{r}=1)$ dapat dituliskan sebagai berikut:

$$
\mathrm{Y}_{\mathrm{t}}=\frac{\omega_{2,1}(\mathrm{~B}) \mathrm{B}^{0}}{\delta_{1,1}(B)} \mathrm{S}_{1, \mathrm{t}}+\frac{\omega_{0,2}(B) \mathrm{B}^{3}}{\delta_{1,2}(B)} \mathrm{S}_{2, \mathrm{t}}+\frac{\varepsilon_{\mathrm{t}}}{\phi(B)} \text {, dengan } \varepsilon_{\mathrm{t}} \sim \mathrm{WN}\left(0, \sigma^{2}\right)
$$

Estimator-estimator yang akan dicari nilainya adalah : $\sigma^{2}, \phi_{1}, \phi_{2}, \omega_{0,1}, \omega_{1,1}, \omega_{2,1}$, $\omega_{0,2}$, dan $\delta_{1,1}, \delta_{1,2}$. Berdasarkan persamaan diatas, dapat diperoleh:

$$
\varepsilon_{\mathrm{t}}=\left(\phi(B) . \mathrm{Y}_{\mathrm{t}}-\phi(B) \omega_{2,1}(\mathrm{~B})\left(\delta_{1,1}(B)\right)^{-1} \mathrm{~S}_{1, \mathrm{t}-0}-\phi(B) \omega_{0,2}(\mathrm{~B})\left(\delta_{1,2}(B)\right)^{-1} \mathrm{~S}_{2, \mathrm{t}-\mathrm{3}}\right)
$$

Untuk selanjutnya dapat dituliskan:

$$
\mathrm{L}=\prod_{t=p+1}^{n} \frac{1}{\sqrt{2 \pi} \sigma} \exp \left(-\frac{1}{2}\left(\frac{\varepsilon_{\mathrm{t}}}{\sigma}\right)^{2}\right)=\frac{1}{2 \pi^{(n-p) / 2} \sigma^{n-p}} \exp \left(-\frac{1}{2 \sigma^{2}} \sum_{t=p+1}^{n} \varepsilon_{\mathrm{t}}^{2}\right)
$$

$\log \mathrm{L}=-\left(\frac{n-p}{2}\right) \log (2 \pi)-(n-p) \log \sigma-$

$$
\frac{1}{2 \sigma^{2}} \sum_{t=p+1}^{n}\left(\phi(B) . \mathrm{Yt}-\phi(B) \omega_{2,1}(\mathrm{~B})\left(\delta_{1,1}(B)\right)^{-1} \mathrm{~S}_{1, \mathrm{t}}-\phi(B) \omega_{0,2}(\mathrm{~B})\left(\delta_{1,2}(B)\right)^{-1} \mathrm{~S}_{2, \mathrm{t}-3}\right)^{2}
$$

\section{Pembahasan}

Pergerakan harga saham Pelayaran Tempuran Emas tbk (TMAS.JK) telah diduga terdapat pengaruh intervensi. hal ini terlihat dari pergerakannya yang bergerak sangat tinggi dalam waktu yang relatif cepat. Berikut ini dugaan intervensi yang mempengaruhi laju pergerakan harga saham TMAS. Dimana intervensinya adalah sebagai berikut:

1. Tanggal 11 Agustus 2014, yang diduga sebagai dampak dari terpilihnya pasangan Joko Widodo-Jusuf Kalla sebagai presiden dan wakil presiden pada tanggal 22 Juli 2014.

2. Pidato Jokowi di forum APEC mengenai program tol laut, dan menawarkan investasi dibidang pembangunan pelabuhan kepada bangsa asing : 10 November 2014.

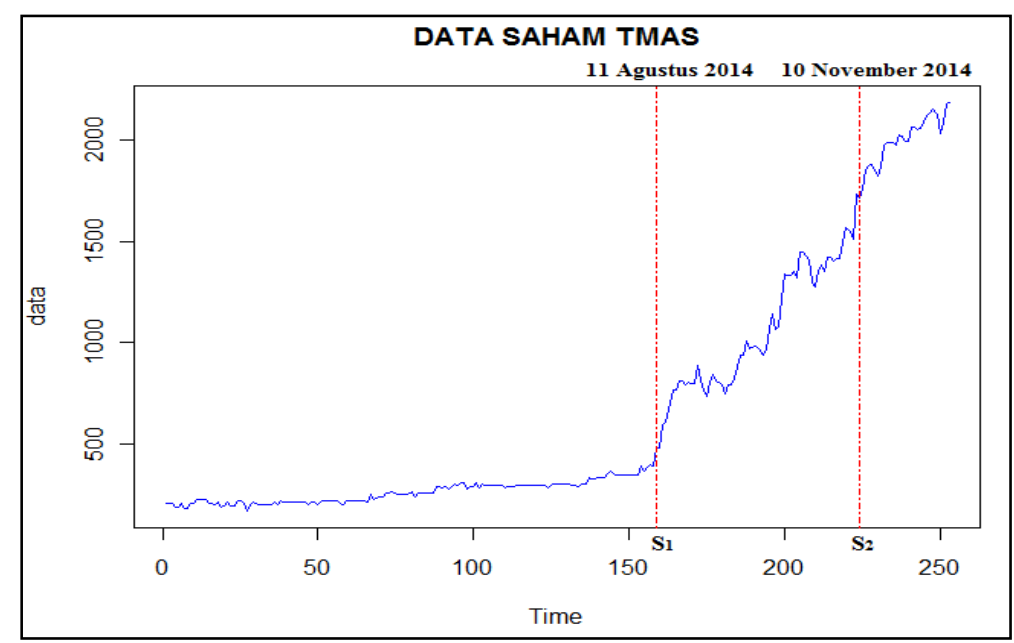

Gambar 1: Grafik Data Saham Harian TMAS, 1 Januari 2014 -16 Januri 2015. 
Dari Gambar 1 diatas, dapat dijelaskan bahwa intervensi pertama disimbolkan dengan $S_{1}$, intervensi kedua disimbolkan dengan $S_{2}$. terlihat bahwa setelah intervensi pertama terjadi kenaikan harga saham, hal ini menyatakan bahwa keputusan terpilihnya Joko Widodo sebagai Presiden RI berdampak positif. Setelah intervensi II pun terlihat pergerakan harga saham mengalami kenaikan yang cukup tinggi. Hal inilah yang mendasari penulis untuk menerapkan metode analisis intervensi pada data time series tersebut.

Setelah dilakukan pengolahan data melalui tahap identifikasi, estimasi parameter dan cek diagnosa, maka untuk data sebelum ada intervensi diperoleh model ARIMA $(2,1,0)$ sebagai model yang terbaik.

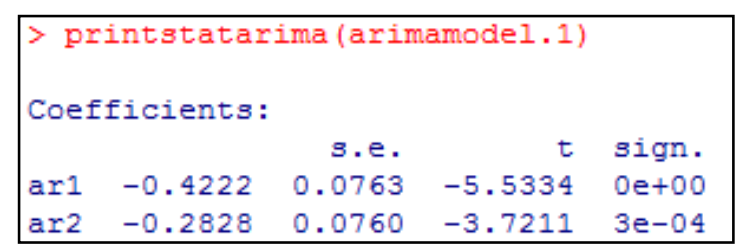

Gambar 2: Output Estimasi Parameter Model Arima

Secara matematik, model ini dapat ditulis seperti berikut :

$$
\begin{aligned}
& (1-B)\left(1-\phi_{1} B-\phi_{2} B^{2}\right) X_{t}=\varepsilon_{t} \\
& X_{t}=\phi_{1} X_{t-1}+X_{t-1}-\phi_{1} X_{t-2}+\phi_{2} X_{t-2}-\phi_{2} X_{t-3}+\varepsilon_{t} \\
& X_{t}=-0.4222 X_{t-1}+X_{t-1}+0.1394 X_{t-2}+0.2828 X_{t-3}+\varepsilon_{t}
\end{aligned}
$$

\subsection{Analisis Intervensi I}

peristiwa ditetapkannya pasangan Joko Widodo-Jusuf Kalla sebagai pemenang pemilu 2014. Adapun penetapannya adalah tanggal 11 Agustus 2014. Dalam hal ini, peristiwa tersebut merupakan bentuk fungsi step. Langakah pertama pemodelannya adalah menentukan orde dugaan $b$, $s$, dan $r$ dari model intervensi pertama. Untuk menentukan orde intervensi pertama dapat dilihat melalui diagram dari residual pada Gambar 3 dibawah ini.

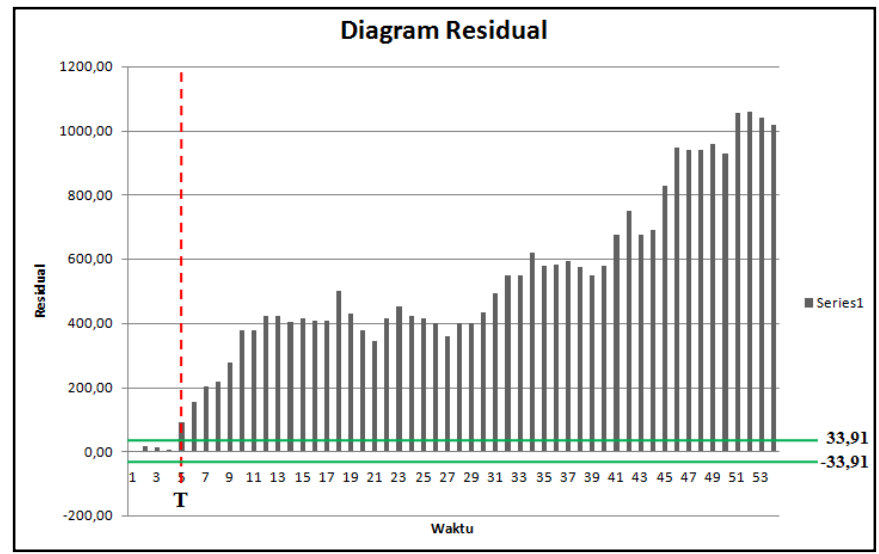

Gambar 3 : Diagram Residual dari Harga Saham Harian TMAS, Setelah Intervensi Pertama dan Sebelum Intervensi Kedua. 
Dari Gambar 3, dapat diduga bahwa orde model intervensi fungsi step adalah $b=0, s=5, r=1$. Hal ini terlihat dari saat $T$ garis residualnya sudah melewati batas 3 RMSE $=33,91$. Sehingga dugaan awal modelnya adalah analisis intervensi fungsi step $(b=0, s=5, r=1)$ dengan model sebelum intervensi adalah ARIMA $(2,1,0)$.

\begin{tabular}{|lrrrr|}
\hline C pvalue (model.2) & & & \\
Coefficients: & & & \\
ar1 & -0.2793 & 0.0665 & -4.2000 & 0.0000 \\
ar2 & -0.2340 & 0.0676 & -3.4615 & 0.0006 \\
step-AR1 & 0.6919 & 0.0789 & 8.7693 & 0.0000 \\
step-MA0 & 0.2183 & 0.0485 & 4.5010 & 0.0000 \\
step-MA1 & -0.1584 & 0.0690 & -2.2957 & 0.0226 \\
step-MA2 & 0.1732 & 0.0562 & 3.0819 & 0.0023 \\
\hline
\end{tabular}

Gambar 4: Output Estimasi Parameter Model Intervensi I

Setelah dilakukan pengolahan data melalui tahap identifikasi, estimasi parameter dan cek diagnosa, maka diperoleh model yang terbaik adalah model analisis intervensi fungsi step $(b=0, s=2, r=1)$ dengan model sebelum intervensi adalah ARIMA $(2,1,0)$. Secara matematik, model ini dapat ditulis seperti berikut :

$$
\begin{gathered}
X_{t}=\frac{\omega_{0}-\omega_{1} B-\omega_{2} B^{2}}{1-\delta_{1} B} S_{1, t}+\frac{\varepsilon_{t}}{(1-B)\left(1-\phi_{1} B-\phi_{2} B^{2}\right)} \\
X_{t}=\frac{0,2183-(-0,1584) B-0,1732 B^{2}}{1-0,6919 B} S_{1, t}+\frac{\varepsilon_{t}}{(1-B)\left(1-(-0,2793) B-(-0,2340) B^{2}\right)}
\end{gathered}
$$

Bentuk persamaan diatas juga dapat diuraikan menjadi:

$$
\begin{aligned}
X_{\mathrm{t}}= & \omega_{0} S_{1, \mathrm{t}}-\left(\omega_{0}+\omega_{0} \phi_{1}+\omega_{1}\right) S_{1, \mathrm{t}-1}+\left[\omega_{0}\left(\phi_{1}-\phi_{2}\right)+\omega_{1}+\omega_{1} \phi_{1}-\omega_{2}\right] \mathrm{S}_{1, \mathrm{t}-2} \\
& +\left[\omega_{0} \phi_{2}-\omega_{1}\left(\phi_{1}-\phi_{2}\right)+\omega_{2}+\omega_{2} \phi_{1}\right] S_{1, t-3-}-\left[\omega_{1} \phi_{2}+\omega_{2}\left(\phi_{1}-\phi_{2}\right)\right] S_{1, t-4} \\
& -\omega_{2} \phi_{2} S_{1, \mathrm{t}-5}+X_{\mathrm{t}-1}+\left(\phi_{1}+\delta_{1}\right) X_{\mathrm{t}-1}-\left[\left(\phi_{1}-\phi_{2}\right)+\delta_{1}+\left(\phi_{1} \delta_{1}\right)\right] X_{\mathrm{t}-2}-\left[\phi_{2}-\delta_{1}\left(\phi_{1}-\phi_{2}\right)\right] \\
& X_{\mathrm{t}-3}+\left(\phi_{2} \delta_{1}\right) X_{\mathrm{t}-4}+\varepsilon_{\mathrm{t}}-\delta_{1} \varepsilon_{\mathrm{t}-1} \\
X_{\mathrm{t}}= & (0,2183) \mathrm{S}_{1, \mathrm{t}}+(0,001071) \mathrm{S}_{1, \mathrm{t}-1}-(0,297248) \mathrm{S}_{1, \mathrm{t}-2}+(0,0665675) \mathrm{S}_{1, \mathrm{t}-3-} \\
& (0,0292196) \mathrm{S}_{1, \mathrm{t}-4}+(0,040529) \mathrm{S}_{1, \mathrm{t}-5}+\mathrm{X}_{\mathrm{t}-1}+(0,4126) \mathrm{X}_{\mathrm{t}-1}-(0,4533523) \mathrm{X}_{\mathrm{t}-2}+ \\
& (0,202657) \mathrm{X}_{\mathrm{t}-3}-(0,161905) \mathrm{X}_{\mathrm{t}-4}+\varepsilon_{\mathrm{t}}-(0,6919) \varepsilon_{\mathrm{t}-1}
\end{aligned}
$$

\subsection{Analisis intervensi II}

Setelah diperoleh model analisis intervensi I, maka selanjutnya dapat diperoleh residualnya, guna membuat diagram residual untuk menentukan orde $b, s, r$ analisis intervensi II. Adapun diagram residualnya adalah sebagai berikut: 


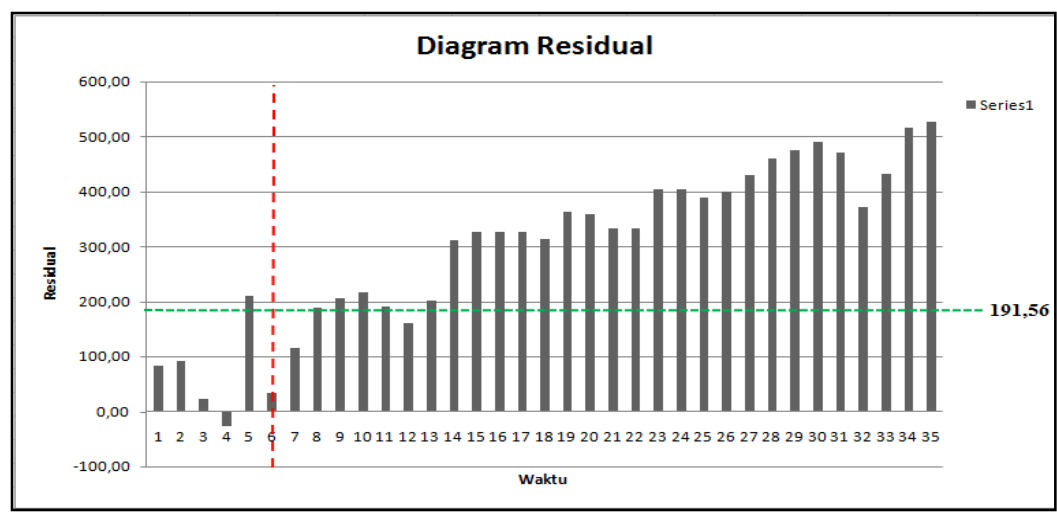

Gambar 5 : Diagram Residual dari Harga Saham Harian TMAS, Setelah Intervensi II.

Dari Gambar 5, dapat diduga bahwa orde model intervensi fungsi step adalah $b=3, s=2, r=0$. Sehingga diperoleh dugaan modelnya yakni: model sebelum intervensi adalah ARIMA $(2,1,0)$, intervensi pertama (fungsi step $(b=0, s=2$, $r=1)$ ), dan intervensi kedua (fungsi step $(b=3, s=2, r=0)$.

\begin{tabular}{|lrrrr|}
\hline \multicolumn{2}{l}{$>$ pvalue (model.3) } \\
Coefficients: & & & \\
ar1 & -0.2734 & 0.0617 & -4.4311 & 0.0000 \\
ar2 & -0.2327 & 0.0626 & -3.7173 & 0.0002 \\
step-AR1 & 0.6915 & 0.0754 & 9.1711 & 0.0000 \\
step-MA0 & 0.2182 & 0.0461 & 4.7332 & 0.0000 \\
step-MA1 & -0.1582 & 0.0653 & -2.4227 & 0.0161 \\
step-MA2 & 0.1734 & 0.0533 & 3.2533 & 0.0013 \\
step.1-AR1 & 0.8731 & 0.1964 & 4.4455 & 0.0000 \\
step.1-MA0 & 0.0296 & 0.0283 & 1.0459 & 0.2966 \\
\hline
\end{tabular}

Gambar 6: Output Estimasi Parameter Model Intervensi II

Setelah pengolahan data melalui tahap identifikasi, estimasi parameter dan cek diagnosa ahirnya terpilih salah satu model yang terbaik untuk digunakan. Yakni model analisis intervensi fungsi step, ARIMA $(2,1,0)$, intervensi pertama (fungsi step $(b=0, s=2, r=1)$ ), dan intervensi kedua (fungsi step $(b=3, s=0, r=1)$. Dimana modelnya dapat dituliskan sebagai berikut:

$$
\begin{gathered}
X_{t}=\frac{\omega_{0}-\omega_{1} B-\omega_{2} B^{2}}{1-\delta_{1} B} S_{1, t}+\frac{\omega_{0} B^{3}}{1-\delta_{1} B} S_{2, t}+\frac{\varepsilon_{t}}{(1-B)\left(1-\phi_{1} B-\phi_{2} B^{2}\right)} \\
X_{t}=\frac{0,2185+0,1582 B-0,1734 B^{2}}{1-0,6915 B} S_{1, t}+\frac{0,0296}{1-0,8731 B} S_{2, t-3}+\frac{\varepsilon_{t}}{(1-B)\left(1+0,2734 B+0,2327 B^{2}\right)}
\end{gathered}
$$

Dimana:

$$
\begin{aligned}
& \mathrm{S}_{1, \mathrm{t}}=\left\{\begin{array}{l}
0, \quad t<11 \text { Agustus } 2014 \\
1, \quad t \geq 11 \text { Agustus } 2014
\end{array}\right. \\
& \mathrm{S}_{2, \mathrm{t}-3}= \begin{cases}0, & t<10 \text { November } 2014 \\
1, & t \geq 10 \text { November } 2014\end{cases}
\end{aligned}
$$


Berdasarkan hasil diatas, maka dapat diperoleh hasil bahwa untuk melakukan peramalan (forecasting) data saham TMAS.JK model terbaik yang dapat digunakan adalah sebagai berikut :

$\mathrm{X}_{\mathrm{t}}=\frac{0,2185+0,1582 \mathrm{~B}-0,1734 \mathrm{~B}^{2}}{1-0,6915 B} \mathrm{~S}_{1, \mathrm{t}}+\frac{0,0296}{1-0,8731 B} \mathrm{~S}_{2, \mathrm{t}-3}+\frac{\varepsilon_{\mathrm{t}}}{(1-\mathrm{B})\left(1+0,2734 \mathrm{~B}+0,2327 \mathrm{~B}^{2}\right)}$

Analisis data ini memberikan gambaran bahwa suatu peristiwa/kebijakan pemerintah dapat menjadi intervensi (memberikan dampak) kepada pergerakan ekonomi pada umumnya atau harga saham pada khususnya.

\section{Kesimpulan}

1. Terbukti bahwa program Tol Laut memberikan efek terhadap pergerakan harga saham di bidang pelayaran.

2. Terdapat 2 kejadian intervensi yang mengakibatkan pergerakan harga saham TMAS.JK, yakni:

- Tanggal 11 Agustus 2014, yang diduga sebagai dampak dari terpilihnya pasangan Joko Widodo-Jusuf Kalla sebagai presiden dan wakil presiden RI pada tanggal 22 Juli 2014.

- Pidato Presiden Joko Widodo di forum APEC mengenai program tol laut, dan menawarkan investasi dibidang pembangunan pelabuhan kepada bangsa asing : 10 November 2014.

3. Model yang terbentuk adalah model analisi intervensi multi input fungsi step, dimana modelnya ARIMA $(2,1,0)$, stepI $(b=0, s=2, r=1)$, stepII $(b=3, s=0 r=1)$.

\section{Daftar Pustaka}

[1] Bain, L.J. dan Engelhardt, M. 1992. Introduction to Probability and Mathematical Statistics. Duxbury Press. Boston.

[2] Box, G.E.P. Jenskins, G.M. and Reinsel, G.C. 1994. Time Series Analysis Forecasting and Control: Third Edition. Prentice-Hall International, Inc. United States of America.

[3] Box, G.E.P. and Tiao, G.C. 1975. Intervention Analysis With Applications to Economic and Environmental Problems. Journal of American Statistical Association. Marc 1975, Volume 70, Number 349 Invited Paper, Theory and Methods Section.

[4] Subanar. 2013. Statistika Matematika. Graha Ilmu.Yogyakarta.

[5] Wei, W.W.S. 2006. Time Series Analysis: Univariate and Multivariate Methods: Second Edition. Addison-Wesley Publishing Company, Inc. California. 